\title{
Doxorubicin-Cisplatin Regimen
}

National Cancer Institute

\section{Source}

National Cancer Institute. Doxorubicin-Cisplatin Regimen. NCI Thesaurus. Code C64790.

A regimen consisting of doxorubicin and cisplatin used for the treatment of malignant

mesothelioma; also used with or without surgical resection for the treatment of

childhood hepatoblastoma. 